\title{
LA DISPUTA POR "MACEDONIA”. ORIGEN, DESARROLLO Y CONSECUENCIAS DE UN CONFLICTO IDENTITARIO
}

\author{
Antonio Gil Fons \\ Alejandra Nieves Camacho
}

\section{INTRODUCCIÓN}

En EL CORAZÓn DE Europa, en unos Balcanes históricamente complejos y conflictivos, una disputa entre dos Estados se encuentra enquistada desde su inicio hasta nuestros días. El motivo: el nombre de un país. Tanto Grecia como la Antigua República Yugoslava de Macedonia $\left(\mathrm{ARYM}^{1}\right)$ mantienen reivindicaciones sobre el término "Macedonia". Atenas nunca ha aceptado que sus vecinos del norte empleen dicha palabra en su nombre constitucional de "República de Macedonia”. El gobierno de Skopie se niega a renunciar a ella. De esta divergencia por el nombre de un país, que puede parecer trivial, se han derivado intensos enfrentamientos dialécticos, embargos, bloqueos y vetos, conque, actualmente, tanto la política interna como las relaciones exteriores de estos dos Estados, ya sean bilaterales o internacionales, se encuentran influenciadas, en gran medida, por esta cuestión. Es una disputa no sólo por una palabra, sino por el legado histórico y cultural de los reinos de Filipo II y Alejandro Magno.

${ }^{1}$ Los autores, buscando permanecer neutrales en la disputa planteada entre Skopie y Atenas, utilizarán, en el presente artículo, el nombre Antigua República Yugoslava de Macedonia (ARYM; por sus siglas en inglés, FYROM) para referirse al país que constitucionalmente se llama "República de Macedonia". La decisión ha sido tomada con base en que es la designación que dicho país mantiene en las Naciones Unidas. 
La explicación de la importancia que se le da a un nombre lo debemos hallar en lo que Pierre Renouvin y Jean-Baptiste Duroselle denominaban "fuerzas profundas". Para ambos historiadores, dicho término se aplica a una serie de elementos que "han formado el marco de las relaciones entre grupos humanos y que, en gran medida han determinado su naturaleza". ${ }^{2}$ Sin duda, la importancia que ambas partes le dan a esta disputa está claramente vinculada a dos de ellos: el sentimiento nacional y el nacionalismo imperante en ambos países.

Las particulares características del conflicto y sus consecuencias merecen el presente artículo. Se pretende, en un primer momento, exponer detalladamente los orígenes y evolución del conflicto para, a continuación, analizar las medidas adoptadas por los sucesivos gobiernos de la ARYM para hacer frente a esta cuestión que mantiene a la pequeña república balcánica fuera de la Unión Europea y de la Organización del Tratado del Atlántico Norte, y con un nombre diferente al que señala su constitución nacional en la Organización de Naciones Unidas.

Al finalizar la lectura de este artículo, se confía en que el lector pueda observar el origen, desarrollo, situación actual e importantes implicaciones de la disputa soberana que ambas partes mantienen, así como la influencia de los sentimientos nacionales y del nacionalismo exacerbado, existentes como "fuerzas profundas" tanto en Grecia como en la ARYM, en la configuración y pervivencia del conflicto.

\section{LA DISPUTA POR EL TERRITORIO DE LA MACEDONIA HISTÓRICA}

Insertada dentro de los territorios del Imperio otomano, la Macedonia histórica, la de Filipo II y Alejandro Magno, pronto fue ambicionada por los nacionalismos griego, búlgaro y serbio, que habían alcanzado su auge en el siglo xix. La región geográfica conocida como Macedonia es el único territorio donde los Balcanes pueden ser atravesados de norte a sur y de oeste a este, desde Belgrado a

${ }^{2}$ Pierre Renouvin y Jean-Baptiste Duroselle, Introducción a la historia de las relaciones internacionales, México, FCE, 2000. 


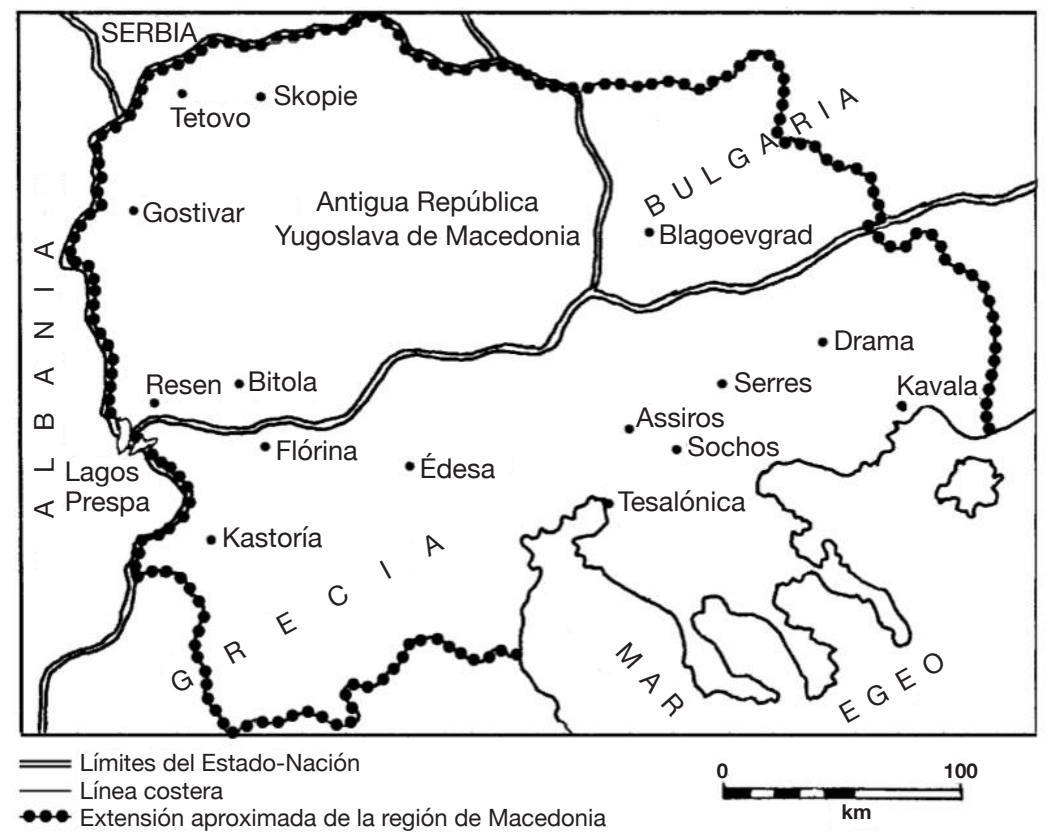

Tesalónica y desde Durres a Estambul, en una encrucijada de imperios, culturas y religiones. ${ }^{3}$

En un contexto de decadencia otomana, y tras las dos guerras balcánicas de 1912 y 1913 y la Primera Guerra Mundial, según Constantinos Mitsotakis, la Macedonia histórica quedó dividida en tres: la mitad en Grecia, un 20\% en Bulgaria y el $30 \%$ restante en lo que se llama la "provincia de Vardar", 4 integrada dentro de la habitualmente denominada Yugoslavia. ${ }^{5}$ Tras la Segunda Guerra Mundial, con la derrota del Eje y el establecimiento de la República

${ }^{3}$ Ángel Santa Cruz, "Macedonia: un crisol demasiado apetecible para sus vecinos”, ElPaís, 19 de mayo de 1996, disponible en http:/ / elpais.com/diario/1996/ 05/19/internacional/832456806_850215.html

${ }^{4}$ Según Mitsotakis, debido a la existencia de un río del mismo nombre.

${ }^{5}$ Entre 1918 y 1929, dicho territorio recibía el nombre oficial de Reino de los Serbios, Croatas y Eslovenos. A partir de 1929 se convertirá en el Reino de Yugoslavia, que existió hasta la ocupación nazi de 1941 en el marco de la Segunda Guerra Mundial. Luis Matíaas López, "La inestabilidad en los Balcanes, amenaza a Grecia", 
Federativa Socialista de Yugoslavia en 1945, el mariscal Josip Broz, Tito, otorgó a los habitantes de la Macedonia yugoslava el derecho a tener una república y nacionalidad propia,${ }^{6}$ constituyendo así la República Socialista de Macedonia.

\section{LA MACEDONIA HISTÓRICA Y GEOGRÁFICA EN RELACIÓN CON LOS ESTADOS CONTEMPORÁNEOS DE LA REGIÓN7}

Sin embargo, cuando la Yugoslavia socialista comenzó a verse devorada por los nacionalismos extremos a finales de los ochenta y principios de los noventa, el parlamento de Skopie convocó un referéndum de independencia para el 8 de septiembre de $1991 .{ }^{9}$ En dicha fecha, las urnas arrojaron un abrumador $96.4 \%$ a favor de la independencia con una participación del electoral de $75.7 \% .^{10}$ Así, en diciembre de 1991, la constitucionalmente conocida como República de Macedonia solicitaba el

El País, 5 de junio de 1992, disponible en http://elpais.com/diario/1992/06/05/ internacional/707695202_850215.html

${ }^{6}$ La República Federativa Socialista de Yugoslavia se componía de seis subdivisiones administrativas conocidas como "repúblicas". Éstas eran la República Socialista de Bosnia y Herzegovina, la República Socialista de Croacia, la República Socialista de Macedonia, la República Socialista de Montenegro, la República Socialista de Eslovenia y, finalmente, la República Socialista de Serbia. Ésta última se dividía, además, en dos provincias autónomas: Kosovo y Vojvodina. Véase además: Mirjana Tomic, "Macedonia, ante los malos augurios", El País, 5 de julio de 1992, disponible en http://elpais.com/diario/1992/07/05/internacional/710287220_ 850215.html

${ }^{7}$ Jane K. Cowan, Macedonia: The Politics of Identity and Difference, Londres, Pluto Press, 2000, p. XviII.

${ }^{8}$ Mirjana Tomic, "Vía libre al Ejército yugoslavo para detener los enfrentamientos entre serbios y croatas", El País, 6 de mayo de 1991, disponible en http:/ / elpais.com/diario/1991/05/06/internacional/673480821_850215.html

9 "Incidentes aislados empañan un precario alto el fuego en Croacia”, El País, 8 de agosto de 1991, disponible en http:/ / elpais.com/diario/1991/08/08/portada/681602402_850215.html

${ }^{10}$ Dieter Nohlen y Philip Stöver, Elections in Europe: A Data Handbook, BadenBaden, Nomos, 2010, p. 1278. 
reconocimiento de su independencia por parte de la Comunidad Europea. ${ }^{11}$

LA COMPLEJA RELACIÓN REGIONAL

A partir de ese momento, Macedonia se convirtió en un problema balcánico y europeo. Como era de esperar, Serbia no reconoció la secesión de dicha república y durante los conflictos yugoslavos siempre mantuvo su amenaza contra ella. En el caso de Bulgaria, inmersa en importantes cambios internos tras la caída del régimen comunista en 1989, el gobierno de Sofía se limitó a reconocer a la república balcánica, pero mantuvo su postura histórica de considerar a sus habitantes como búlgaros. Mucho más problemática fue la reacción de Grecia, que se negó al reconocimiento del nuevo Estado y se opuso tenazmente a su inserción internacional, ${ }^{12}$ anunciando su intención de utilizar todos los medios a su alcance para evitar su reconocimiento por parte de otros países. Desde el gobierno de Atenas se afirmaba que la Macedonia histórica había sido integrante del mundo heleno y que el concepto de nación macedonia era una invención reciente realizada por los comunistas. Además, en Grecia nunca había existido una minoría macedonia con entidad propia sino, como mucho, pequeñas comunidades de eslavos helenizados. Finalmente, se señalaba que Skopie no tenía ningún derecho sobre el nombre y los símbolos de la Macedonia histórica pues gran parte de su territorio pertenecía a Grecia. El uso de estos elementos era interpretado por Atenas como un cuestionamiento de las fronteras existentes y le hacía temer futuras reivindicaciones territoriales. ${ }^{13}$

Grecia planteó tres condiciones para el reconocimiento de la nueva república: el fin del uso unilateral del nombre Macedonia

${ }^{11}$ Mirjana Tomic, "Alemania reconoce a Eslovenia y Croacia”, El País, 24 de diciembre de 1991, disponible en http://elpais.com/diario/1991/12/24/internacional/693529219_850215.html

${ }^{12}$ Carlos Flores Juberías, "Macedonia: entre la crisis y la consolidación”, Revista CIDOB d'Afers Internacionals, núm. 51-52, 2000-2001.

${ }^{13}$ Loc. cit. 
por parte del nuevo Estado, modificaciones en el contenido del preámbulo y de algunos artículos de la Constitución de 1991, que abogaban por la protección de las "minorías macedonias" en otros países, y cambios en los símbolos de la bandera nacional y de las monedas del nuevo Estado. ${ }^{14}$

En resumen, Serbia reconocía la nación macedonia pero no el Estado independiente; Bulgaria sí reconocía el Estado independiente pero no la nación macedonia; y, por último, Grecia no reconocía ni lo uno ni lo otro. ${ }^{15}$ Como afirmó Tomic, "Macedonia no ha tenido ninguna iniciativa política audaz en la crisis yugoslava y, sin embargo, está presa de todas las contradicciones balcánicas, rodeada de las naciones que cuestionan su cultura y existencia, aspirando a amputarle parte del territorio". ${ }^{16}$ De esta manera, al mismo tiempo que la nueva república tenía que afrontar toda una serie de retos internos y externos debido a la violenta inestabilidad existente en los Balcanes, la cuestión del nombre se abría paso como uno de los principales retos.

\section{Posturas opuestas}

El gobierno de Atenas justificaba su postura con base en diversas cuestiones. Desde un punto de vista histórico, Grecia afirmaba que el nombre de "Macedonia" debería reservarse en exclusiva a una parte de los ciudadanos griegos, ya que dicho concepto se encuentra asociado con el reino de Macedonia de Filipo II y Alejandro Magno, que no guardan relación alguna con los eslavos que habitan en la república balcánica. Además, acusaba a dicho país de apropiarse de símbolos de la cultura griega sin permiso, como el uso del Sol de Vergina de Filipo II, ${ }^{17} \mathrm{y}$ de tergiversar la historia. Desde el punto de vista de la cuestión territorial, ya la Yugoslavia de

${ }^{14}$ Loc. cit.

${ }^{15}$ Loc. cit.

${ }^{16}$ Mirjana Tomic, "Yugoslavia, un paisaje desintegrado", El País, 3 de junio de 1992, disponible en http://elpais.com/diario/1992/06/03/internacional/7075 22406_850215.html

${ }^{17} \mathrm{El}$ "Sol de Vergina" o "estrella argeáda” es un sol simbólico de dieciséis ra- 
Tito había reclamado territorios a la Macedonia griega y a la región del Pirin en Bulgaria, ${ }^{18}$ creando un importante antagonismo tanto con Atenas como con Sofía. En el año de 1957, Tito llegó a insinuar la idea de apoyar la creación de una República de Macedonia independiente con capital en la ciudad griega de Salónica. ${ }^{19}$ Con la independencia de la república balcánica, la nueva Constitución de 1991 planteaba para Atenas una amenaza directa al hablar de la protección de las minorías macedonias en otros Estados, un deseo velado, según Grecia, de las ambiciones territoriales del gobierno de Skopie. La difusión de libros escolares y publicaciones oficiales donde se mostraba a la nueva república como una nación ocupada por otras naciones no ayudaba a rebajar las preocupaciones griegas.

Además, según Atenas, los macedonios griegos verían violado su derecho a la autodeterminación por parte de las autoridades de Skopie. Para los nacionalistas griegos, el uso del nombre de Macedonia supone una apropiación y falsificación del pasado con el objetivo de expandir el poder de los eslavos de Skopie hacia los territorios de los macedonios griegos. ${ }^{20}$ Finalmente, el gobierno de Atenas señalaba que hay toda una serie de diversos grupos étnicos que, por vivir en el territorio de la Macedonia histórica, que comprende las actuales Grecia, Bulgaria, Albania y en la república balcánica, reciben el nombre de "macedonios". ${ }^{21}$ Por ello, Atenas argumentaba la necesidad de usar el término de "macedonio" con un adjetivo para dotarlo de mayor precisión. Así, el gobierno griego suele utilizar el término "eslavomacedonio" para describir a los habitantes de la república balcánica. ${ }^{22}$

yos vinculado a Filipo II, padre de Alejandro Magno. Fue descubierta en 1977 durante unas excavaciones en Vergina, en la Macedonia griega.

${ }^{18}$ James Minahan, Miniature Empires, Westport, Greenwood, 1998.

19 "Greek Macedonia 'Not a Problem”", The Times, 5 de agosto de 1957.

${ }^{20}$ Loring M. Danforth, The Macedonian Conflict, Princeton, Princeton University Press, 1997.

${ }^{21}$ Como la importante minoría albanesa de la ARYM que, al habitar legalmente en ella, en teoría podrían ser calificados de "macedonios".

${ }^{22}$ U.S. Department of State, "Bureau of Democracy, Human Rights, and Labor 2005", 8 de marzo de 2006, disponible en http://www.state.gov/j/drl/rls/ hrrpt/2005/61651.htm 
Desde el gobierno de Skopie, sin negar su raíz eslava, se hacía de las expresiones "macedonio", "cultura macedonia" o "nacionalidad macedonia" -que implicaban una lengua, cultura y religión particulares- sus elementos identificativos y de unión con su diáspora frente a otros pueblos balcánicos y se negaba a emplear, de forma oficial, gentilicios compuestos como "eslavomacedonios". ${ }^{23}$

Ya en 1991, cuando la Comisión de arbitraje de la conferencia sobre Yugoslavia afirmó que la república balcánica satisfacía las condiciones para su reconocimiento internacional, Atenas mostró su clara oposición a dicha declaración por sus disputas sobre el nombre del país, su constitución y su bandera y trató de alinear al conjunto de la CEE con su perspectiva. El 13 de abril de 1992 los principales partidos políticos de Grecia pactaron que la palabra "Macedonia" no podría ser utilizada por sus vecinos del norte. ${ }^{24}$ Desde Atenas se propusieron, en este sentido, los nombres de "República de Vardar" o de "República de Skopie", propuestas que la otra parte rechazó al negarse a renunciar al uso del término de "Macedonia". Al mismo tiempo, la diplomacia griega y la diáspora griega, especialmente la de Estados Unidos, comenzaban a movilizarse para evitar el reconocimiento internacional de la república balcánica. ${ }^{25}$

\section{LA ONU BIEN VALE DENOMINARSE ARYM}

Durante el año de 1992, el término de "Antigua República Yugoslava de Macedonia” (ARYM) comenzó a popularizarse en los círculos internacionales al ser empleado por el Fondo Monetario Internacional

${ }^{23}$ Loring M. Danforth, "National Conflict in a Transnational World: Greeks and Macedonians at the Conference for Security and Cooperation in Europe”, disponible en http://www.gate.net/ mango/Danforth_National_Conflict. htm

24 Theodore A. Couloumbis, Theodore C. Kariotis y Fotini Bellou, Greece in the Twentieth Century, Nueva York, Routledge, 2003.

${ }^{25}$ John Shea, Macedonia and Greece: The Struggle to Define a New Balkan Nation, Londres, McFarland, 1997. 
y el Banco Mundial en sus referencias a la nueva república. En ese mismo año, el Consejo Europeo expresaba su disposición de "reconocer a la Antigua República Yugoslava de Macedonia y sus fronteras", siempre que usara un nombre que no incluyera "Macedonia". ${ }^{26}$ También fríamente recibió la Organización de Naciones Unidas (ONU) la petición de ingreso de la nueva república el 30 de julio de 1992, en un momento donde sólo Turquía y Bulgaria reconocían su nombre constitucional.

La denominación de ARYM fue propuesta por Reino Unido, Francia y España para que fuera el nombre con el que la república balcánica accediera a las Naciones Unidas, proyecto que fue, "en principio", aceptado por Grecia en enero de 1993, a falta de clarificar diversas cuestiones como las reivindicaciones territoriales o el uso de símbolos que Atenas considera como propios. ${ }^{27}$ Por otra parte, la denominación de ARYM no fue del agrado de las autoridades de Skopie y el presidente macedonio Gligorov rechazó que asociaran su país a Yugoslavia. ${ }^{28}$

Sin embargo, tras el apoyo inicial que Grecia recibió por parte de sus aliados de la Organización del Tratado del Atlántico Norte (OTAN) y de la Comunidad Económica Europea (CEE), la intransigencia helena sobre la cuestión y las problemáticas consecuencias que se podían derivar en los inestables Balcanes conllevaron el desarrollo de cierta tensión dentro de ambas instituciones. En este sentido, el ministro de Exteriores danés, Uffe Ellemann-Jensen, describió la postura griega como "rídicula" y anunció que diversos miembros de la CEE apoyarían el reconocimiento de la ARYM. ${ }^{29} \mathrm{El}$

26 "Report to the European Council in Lisbon", 1992, disponible en http:// www.europarl.europa.eu/summits/lisbon/li2_en.pdf

${ }^{27}$ Paul Lewis, "Compromise Likely to Take Macedonia into UN", The New York Times, 26 de junio de 1993, disponible en http:/ / www.nytimes.com/1993/01/ 26/ world/compromise-likely-to-take-macedonia-into-un.html

28 ONU, "Practice Relative to Recommendations to the General Assembly Regarding Membership in the United Nations", en Repertoire 12th Supplement 19931995, capítulo viI, disponible en http://www.un.org/french/docs/cs/repertoire/93-95/93-95_7.pdf

${ }^{29}$ Tom Gallagher, The Balkans in the New Millennium: In the Shadow of War and Peace, Nueva York, Routledge, 2005. 
gobierno de Mitsotakis comenzó a verse presionado también en el interior por los sectores más nacionalistas de su partido y del parlamento heleno, que exigían mayor dureza contra la ARYM y los que la apoyaban. En el caso del gobierno de Skopie, la nueva república no podía permanecer más tiempo fuera de la onU y sin un amplio reconocimiento internacional.

El 8 de abril de 1993, tras intensas negociaciones para limar diferencias entre las partes implicadas, la Asamblea General de Naciones Unidas, siguiendo las disposiciones de la resolución 817 del Consejo de Seguridad, admitía como miembro número 181, mediante la resolución 225, a la Antigua República Yugoslava de Macedonia. ${ }^{30} \mathrm{El}$ acuerdo que se había fraguado para la admisión se basaba en cuatro puntos: a) la denominación de "Antigua República Yugoslava de Macedonia" tendría carácter provisional hasta que se resolviera la disputa planteada; ${ }^{31}$ b) dicho término era una referencia neutral a la república balcánica donde, simplemente, se reflejaba el hecho histórico de que dicho país había pertenecido a la antigua Yugoslavia; ${ }^{32}$ c) la denominación sería utilizada de manera obligatoria por la onU pero no compelía a su uso fuera de dicho organismo; ${ }^{33}$ y $d$ ) el término no implicaba conexión alguna entre la ARYM y la nueva República Federal de Yugoslavia. ${ }^{34}$

Una vez en la onU, la ARYM logró progresivamente el reconocimiento internacional por parte de la República Popular China en octubre de 1993, de Dinamarca, Alemania, Francia, Italia, Países Bajos, Reino Unido y Rusia en diciembre de 1993 y de Japón y Australia en febrero y marzo de 1994. Estados Unidos reconoció a la nueva república en febrero de 1994 y, en un ejemplo de la

${ }^{30}$ Ian Jeffries, The Former Yugoslavia at the Turn of the Twenty-First Century, Nueva York, Routledge, 2003.

31 Jochen A. Frowein, Max Planck Yearbook of United Nations Law 1997, Leiden, Martinus Nijhoff Publishers, 1998.

${ }^{32}$ oNU, op. cit.

33 "Report to the European Council in Lisbon", 1992, disponible en http:// www.europarl.europa.eu/summits/lisbon/li2_en.pdf

${ }^{34} \mathrm{ONU}$, op. cit. 
importancia que se le dio al hecho, los canales de televisión y radio interrumpían su emisión para anunciarlo. ${ }^{35}$

Los sectores más nacionalistas de Grecia y la ARYM rechazaron la resolución de la onU. Tampoco el gobierno de Atenas aceptaba la fórmula aprobada. En Grecia, el partido Nueva Democracia de Mitsotakis, que contaba con una exigua mayoría parlamentaria, sufrió el transfuguismo entre sus filas y provocó la caída del gobierno, lo que llevó a la convocatoria anticipada de elecciones legislativas. ${ }^{36}$ En dichos comicios, el opositor Movimiento Socialista Panhelénico (PAsOK, por sus siglas en griego) de Andreas Papandréu ganó; entre sus primeros anuncios figuró el establecimiento de una política más estricta respecto a la ARYM. ${ }^{37}$ En dicha república, las protestas se sucedieron en diversas ciudades en contra de la denominación otorgada. Pese a todo, el parlamento de Skopie aprobó el acuerdo con la onU con 30 votos a favor, 28 en contra y 13 abstenciones. ${ }^{38}$

En respuesta a los reconocimientos internacionales logrados por Macedonia, el 16 de febrero de 1994, el nuevo gobierno griego del socialista Andreas Papandréu decretó el embargo económico unilateral contra la ARYM. Este castigo griego se unía a uno más desastroso que sufría la Skopie desde que, en 1992, la onU decretó un embargo económico sobre Serbia y Montenegro. Hasta ese momento, $90 \%$ del transporte de mercancías macedonias se efectuaba a través de Serbia, la red de suministro eléctrico pasaba

35 Pese a esta tardía formalización de relaciones entre la ARYM y Estados Unidos, trescientos soldados estadounidenses ya se hallaban presentes en la república balcánica desde medio año antes. Mirjana Tomic, "Ahora estoy otra vez aburriéndome”, El País, 8 de marzo de 1994, disponible en http://elpais.com/diario/ 1994/03/08/internacional/76 3081204_850215.html

${ }^{36} \mathrm{El}$ gobierno de Mitsotakis acumulaba acusaciones de nepotismo y corrupción y diversas dimisiones se habían producido. Además, la inflación estaba en dos cifras y la tasa de desempleo se aproximaba a 10\%. La cuestión de la ARYM precipitó que diversos diputados fueran pasando al partido Primavera Política de Samarás (Peter Calvocoressi, Historia política del mundo contemporáneo, Madrid, Akal, 1999).

37 Tom Gallagher, The Balkans in the New Millennium: In the Shadow of War and Peace, Nueva York, Routledge, 2005.

38 John Phillips, Macedonia: Warlords and Rebels in the Balkans, Londres, I. B. Tauris, 2004. 
por Serbia y muchas fábricas eran complementarias de las serbias. ${ }^{39}$ De esta forma, sobre la ARYM recayeron dos embargos: el que le imponía Grecia y el que estaba obligado a cumplir sobre Serbia. La suma de los dos embargos suponía la muerte económica del nuevo Estado y, en la práctica, ante la actitud griega y pese a la presencia de aduaneros internacionales, Skopie tuvo que continuar comerciando con Serbia, aunque en torno a un $50 \%$ menos que antes de la disposición de la onu y estando excluidos los productos estratégicos . ${ }^{40}$

\section{El ACUERdo INTERINO de 1995 y LA NORMALIZACIÓN DE LAS RELACIONES INTERNACIONALES}

El 13 de septiembre de 1995, presionados por Estados Unidos y con la mediación de la oNU, la ARYM y Grecia firmaron un acuerdo interino de mutuo reconocimiento. ${ }^{41}$ Atenas se comprometía a levantar el embargo unilateral, cosa que hizo el 15 de octubre de 1995, y a no bloquear la incorporación de Skopie a los foros y organismo internacionales. Por su parte, la ARYM prometía modificar, en un plazo máximo de treinta días, sus símbolos nacionales y parte de su Constitución. ${ }^{42}$ Finalmente, ambos establecían relaciones diplomáticas. Skopie trató de satisfacer las exigencias

${ }^{39}$ Mirjana Tomic, "Yugoslavia, un paisaje desintegrado", El País, 3 de junio de 1992, disponible en http://elpais.com/diario/1992/06/03/internacional/70752 2406_850215.html

${ }^{40}$ Mirjana Tomic, "Macedonia lucha por su identidad", El País, 7 de marzo de 1994, disponible en http://elpais.com/diario/1994/03/07/internacional/76299 4818_850215.html También: Mirjana Tomic, "Yugoslavia, un paisaje desintegrado", El País, 3 de junio de 1992, disponible en http:/ / elpais.com/diario/1992/06/ 03/internacional/707522406_850215.html

${ }^{41}$ UN, "Greece and the FYR of Macedonia Interim Accord", 1995, disponible en http://peacemaker.un.org/sites/peacemaker.un.org/files/MK_950913_Interim $\% 20$ Accord $\% 20$ between $\% 20$ the $\% 20$ Hellenic $\% 20$ Republic $\% 20$ and $\% 20$ the \%20FYROM.pdf

${ }^{42}$ Eudo Adriazola, “'Satisfacción total' de Grecia por el acuerdo sobre Macedonia”, El País, 15 de septiembre de 1995, disponible en http://elpais.com/diario/ 1995/09/15/internacional/811116003_850215.html 
griegas y, con celeridad, procedió a modificar su Constitución al introducir cláusulas en las que afirmaba no tener ambiciones territoriales y donde renunciaba a interferir en los derechos soberanos y asuntos internos de otros Estados. Además, el Sol de Vergina fue sustituido por un sol con ocho rayos en su bandera nacional y moneda. La cuestión del nombre quedaba aplazada para un futuro acuerdo. Así, el gobierno de Atenas seguiría refiriéndose a sus vecinos como "ARYM", "Skopie" o "eslavomacedonios".

La firma del Acuerdo Interino permitió: a) la entrada de la ARYM en varios organismos internacionales, como la Organización para la Seguridad y Cooperación en Europa (OSCE) o el Consejo de Europa en octubre y noviembre de 1995 respectivamente, ${ }^{43}$ b) supuso el inicio de una intensa relación comercial que convirtió a Grecia en un importante socio comercial para Skopie; ${ }^{44}$ y $c$ ) que la Unión Europea estableciera relaciones formales con la ARYM en enero de $1996 .{ }^{45}$

El camino internacional parecía abierto para la pequeña república cuando en abril de 2001, a raíz de la Cumbre de Zagreb de noviembre de 2000, donde la Unión Europea lanzó el Proceso de Estabilización y Asociación dirigido a los países balcánicos que aún no estaban integrados en dicha organización, se firmó el Acuerdo de Estabilización y Asociación entre la ARYM y la Unión Europea. ${ }^{46}$ De esta forma, Macedonia se convertía en el primer país de la antigua Yugoslavia en firmar este tipo de acuerdo con la Unión Europea y se dirigía con paso firme hacia Europa.

${ }^{43}$ Edmund Jan Osmańczyk, Encyclopedia of the United Nations and International Agreements, Nueva York, Routledge, 2002.

${ }^{44}$ Según datos oficiales del Banco Nacional de la República de Macedonia, en 2014 Grecia fue el tercer proveedor con 667 millones de dólares y el quinto destino de las exportaciones de la ARYM con 226 millones de dólares. (Disponible en http: //www.nbrm.mk/WBStorage/Files/Statistika_NTR_countries_A_2014_fin 2012.xls)

${ }^{45}$ Sin embargo, ya desde octubre de 1992 existían relaciones de bajo perfil a través de un representante de Skopie acreditado en Bruselas.

${ }^{46}$ Consejo de la Unión Europea y Comisión de las Comunidades Europeas, "Decisión del Consejo y de la Comisión, de 23 de febrero de 2004, relativa a la celebración del Acuerdo de estabilización y asociación entre las Comunidades Europeas y sus Estados miembros, por una parte, y la ex República Yugoslava de Macedonia, por otra", Diario Oficial de la Unión Europea, 20 de marzo de 2004. 
Sin embargo, la firma del acuerdo se vio empañada por el progresivo conflicto armado que desde inicios de año enfrentaba a las autoridades de Skopie con la minoría albanesa del norte del país. Pese a que llegaron a producirse intensos enfrentamientos, la rápida mediación de la comunidad internacional, que no quería un nuevo conflicto en los Balcanes, y la buena predisposición de las instituciones y de las fuerzas políticas de la ARYM para hallar una solución pacífica al conflicto derivaron, el 13 de agosto de 2001, en el Acuerdo Marco de Ohrid por el que se establecía una amplia autonomía y nuevos derechos para la minoría albanesa. ${ }^{47}$

Durante los años siguientes, la ARYM destacó por la rapidez y profundidad de las reformas aplicadas y, en diciembre de 2005, el Consejo Europeo de Bruselas acordó conceder a la ARYM el estatus de país candidato a la adhesión. ${ }^{48}$ Sin embargo, no se iniciaron las negociaciones para la misma al mostrarse el Consejo Europeo tremendamente crítico con las irregularidades detectadas en los procesos electorales y con la lentitud de la reforma judicial. Pese a estas cuestiones, no dejaban de reconocerse avances a Skopie, que seguía en la senda europea y occidental con firmeza.

\section{LAS NEGOCIACIONES POR EL NOMBRE, UNA CUESTIÓN PENDIENTE}

En paralelo al proceso mencionado anteriormente, hay que recordar que, en el Acuerdo Interino, la cuestión del nombre de la república balcánica había quedado pendiente de futuras negociaciones. Pese a que ello no impidió que la ARYM lograra el reconocimiento de su nombre constitucional de República de Macedonia por numerosos países, incluyendo el de Estados Unidos en 2004, ${ }^{49}$

47 Carlos Flores Juberías y Marija Atanaskova, "Macedonia y su camino hacia la integración europea: Avances, obstáculos e implicaciones para la región balcánica”, Revista CIDOB d'Afers Internacionals, núm. 96, 2011.

48 Consejo de la Unión Europea, "Brussels European Council. 15/16 december 2005. Presidency Conclusions", Diario Oficial de la Unión Europea, 2005.

${ }^{49}$ En diciembre de 2011 ya eran 133 los países que reconocían el nombre constitucional de República de Macedonia. (United Macedonian Diaspora, "Namibia Becomes 133rd Country to Recognize Macedonia", 21 de diciembre de 
con Grecia no se había producido ningún avance. Por ello, en abril de 2005, Matthew Nimetz, mediador de la onu, sugirió que se acordara el nombre de "República de Macedonia-Skopie". Atenas rechazó la propuesta aunque la consideró como una base para futuras negociaciones. Por su parte, Skopie se negó a aceptarla y propuso que, internacionalmente, se utilizara "República de Macedonia" y que Grecia empleara la denominación de ARYM. ${ }^{50}$ En octubre de ese mismo año, Nimetz presentó una propuesta en un sentido parecido al expuesto por Skopie que fue rechazada categóricamente por Atenas. La mayoría de los partidos políticos de Grecia apoyaban la idea de introducir un adjetivo calificativo en el nombre de sus vecinos pero se oponían a que hubiera dos nombres oficiales. Y mientras esta cuestión no se resolviera, a pesar del Acuerdo Interino, Grecia amenazaba con vetar el acceso de la ARYM a la Unión Europea y la OTAN, tal y como expresó su ministra de Exteriores, Dora Bakoyianni, en septiembre de 2007.

En una nueva ronda de negociaciones, las dos partes se reunieron en febrero de 2008 bajo los auspicios de Nimetz. Se barajaron hasta cinco posibles nombres para la ARYM: "República Constitucional de Macedonia", "República Democrática de Macedonia”, "República Independiente de Macedonia", "República de Nueva Macedonia” y "República de Macedonia del Norte". Sin embargo, fue imposible lograr un compromiso entre las partes y el problema persistió.

Durante la Cumbre de Ministros de Exteriores de la otan, celebrada en Bruselas a principios de marzo de 2008, Dora Bakoyianni afirmó de forma tajante que "a nadie le gusta el veto" y que esperaba "una solución mutuamente aceptable antes de la cumbre que la OTAN celebraría en Bucarest en el mes de abril”, pero "hasta que haya una solución, Grecia será un obstáculo insuperable para las aspiraciones europeas y euroatlánticas de la Antigua

2011, disponible en http://www.umdiaspora.org/index.php/en/name-recognition-contents / 186-namibia-becomes-133rd-country-to-recognize-macedonia)

50 “Greece Considers Macedonia Name", en BBC, 8 de abril de 2005, disponible en http://news.bbc.co.uk/2/hi/europe/4425249.stm 
República Yugoslava de Macedonia". ${ }^{51}$ Dichas amenazas fueron respondidas por una movilización de la diplomacia estadounidense y europea para tratar de evitar el veto griego. Condoleezza Rice, secretaria de Estado estadounidense, afirmaba que "Macedonia se encuentra dentro de los criterios de la OTAN y puede entrar a la Alianza" e instaba a las partes a resolver su disputa. Olli Rhen, comisario europeo de Ampliación, animaba a ser constructivos en la resolución del conflicto y recordaba la necesidad de unanimidad en las cuestiones de ampliación. ${ }^{52}$

Las negociaciones continuaron durante el resto del mes de marzo. Nimetz reducía su propuesta inicial de cinco a dos opciones y añadía una tercera: "República del Norte de Macedonia", "República de Nueva Macedonia” y "República de Macedonia-Skopie". Sin embargo, ninguna de las tres propuestas satisfizo a la ARYM, que las rechazó al decir que no eran soluciones lógicas al problema. ${ }^{53}$ Entre el 21 y el 25 de ese mismo mes sucedieron en Nueva York intensas negociaciones para la resolución de la cuestión. Una nueva propuesta de Nimetz se planteó de acuerdo a tres puntos: ${ }^{54}$ a) el nombre constitucional de "República de Macedonia" estaría escrito en cirílico y sería de uso interno por parte del gobierno de Skopie; b) "República de Macedonia (Skopie) sería usado para las relaciones internacionales y se sugeriría su uso para las relaciones bilaterales. En ningún de los dos casos, ello implicaba cambios en su nombre constitucional; y c) los términos "Macedonia" y "macedonio" serían usados sin restricción alguna por ambos países.

Mientras que la parte griega mostraba sus reticencias a las propuestas porque no cumplía sus expectativas, la ARYM se mostraba dispuesta a llegar a un acuerdo e incluso su parlamento aprobaba una resolución donde anunciaba estar dispuesto a cambiar el nombre del país antes de la Cumbre de Bucarest, que se celebraría en

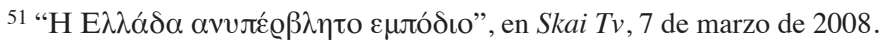

${ }^{52}$ Loc. cit.

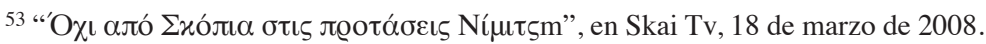

54 "Novi predlog UN oko naziva Makedonije", en Blic, 26 de marzo de 2008, disponible en http://www.blic.rs/Vesti/Svet/35469/Novi-predlog-UN-oko-nazivaMakedonije 
unos días. ${ }^{55}$ Sin embargo, el acuerdo no llegó. De esta manera, la proyección exterior de Macedonia se vio cortada de raíz en dos citas claves: la cumbre de Bucarest de la Organización del Tratado del Atlántico Norte en abril de 2008 y el Consejo Europeo de Bruselas de diciembre de 2009.

\section{LA PROMESA VACÍA DE LA INTEGRACIÓN EUROATLÁNTICA}

En la primera, apadrinada por Estados Unidos, la ARYM esperaba convertirse en miembro de la Alianza. Sin embargo, Grecia presentó la propuesta de aplazar la invitación a Skopie y el secretario general de la oTAN, Jaap de Hoop Scheffer, promovió un acuerdo mutuo entre los miembros donde se afirmaba que el rechazo de la invitación a la ARYM se debía a no haber encontrado una solución a la disputa y se invitaba a las partes a negociar. ${ }^{56}$

Pese a que la OTAN actuó con base al consenso, Skopie no dudó que sus aspiraciones euroatlánticas habían sido frustradas por la posición griega y su amenaza de veto. Por ello, la ARYM decidió llevar a Grecia ante el Tribunal Internacional de Justicia por incumplimiento del artículo 11, párrafo 1 del Acuerdo Interino de 1995. En dicho artículo Grecia se comprometía a dejar de oponerse a la incorporación de la república balcánica a organizaciones internacionales siempre que ésta fuera referida como ARYM, la denominación

55 Spasena Baramova, "Macedonian Parliament to Decide on Name Change at the Last Minute", en The Sofia Echo, 31 de marzo de 2008, disponible en http:/ / sofiaecho.com/2008/03/31/659668_macedonian-parliament-to-decideon-name-change-at-the-last-minute

${ }^{56}$ Sin embargo, en la misma cita sí se invitó a Albania y Croacia a pertenecer a la Alianza. Véase: "La OTAN abre sus puertas a Croacia y Albania y pone en espera a Ucrania y Georgia”, El País, 3 de abril de 2008, disponible en http:/ /internacional.elpais.com/internacional/2008/04/03/actualidad/1207173612_850

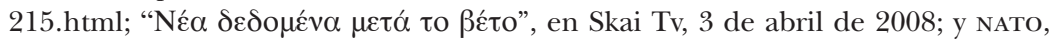
"Bucharest Summit Declaration Issued by the Heads of State and Government Participating in the Meeting of the North Atlantic Council in Bucharest on 3 April 2008", 2008, disponible en http://www.summitbucharest.ro/en/doc_202.html 
prevista en el párrafo $2^{\circ}$ de la resolución del Consejo de Seguridad de las Naciones Unidas $n^{\circ} 817$ de $1993 .^{57}$

Esta denuncia no hizo efecto alguno en el gobierno del conservador Kostas Karamanlís, muy cuestionado internamente en aquellos momentos por los inicios significativos de la devastadora crisis que, hasta la actualidad, sufre Grecia. En la ARYM, el gobierno del primer ministro Nikola Gruevski convocaba elecciones anticipadas ante el fracaso de la Cumbre de Bucarest. En dichos comicios, su coalición electoral "Por una mejor Macedonia" se hizo con la mayoría de los escaños del parlamento, por lo que Gruevski volvió a ser elegido primer ministro.

Las negociaciones entre ambos países se retomaron en octubre de 2008 y nuevamente el mediador Nimetz presentó una propuesta basada en ocho puntos: ${ }^{58}$ a) "República de Macedonia" escrito en macedonio sería oficial sólo para ese país; $b$ ) el nombre del país para eventos oficiales sería "República de Macedonia del Norte"; c) la onu sugeriría el uso de "República de Macedonia del Norte" en las relaciones bilaterales con terceros países; $d$ ) el apelativo de ARYM no sería el nombre oficial del país; $e$ ) los términos "Macedonia" y "macedonio" serían utilizados por ambos países pero sin establecer derecho alguno sobre los mismos; f) los pasaportes de la República de Macedonia incluirían el nombre oficial en macedonio, inglés y francés; $g$ ) Grecia debería apoyar la integración de la ARYM en la Unión Europea y la oTAN; y $h$ ) ambos países no mantendrían ningún tipo de reclamación territorial sobre el otro.

En abril de 2009, el embajador griego en Estados Unidos, Alexandros Mallias, señaló que la denominación "República de Macedonia del Norte" era una buena opción para resolver el conflicto. ${ }^{59}$ Sin embargo, ahora las principales reticencias vinieron de

${ }^{57}$ En diciembre de 2011, el Tribunal dio la razón a la ARYM, aunque no hubo consecuencias al respecto (ONU, "Dictamen favorable de tribunal internacional para la Ex República Yugoslava de Macedonia”, 5 de diciembre de 2011, disponible en http://www.un.org/spanish/News/story.asp?NewsID=22253\#.VSYacJMYHqo).

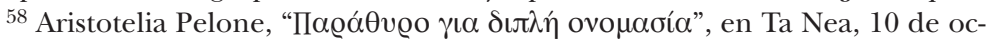
tubre de 2008, disponible en http:/ / www.tanea.gr/news/greece/article/14 03491 $/$ ?iid=2

${ }^{59}$ En estos momentos, Grecia parecía dispuesta a aceptar el término de "Ma- 
parte del gobierno de Skopie, que se mostraba receloso para efectuar los cambios que la propuesta le exigía. ${ }^{60} \mathrm{El}$ acuerdo, nuevamente, no fue posible.

En el Consejo Europeo de Bruselas de diciembre de 2009, la ARYM se presentó con un informe favorable de la Comisión Europea que, además, solicitaba la apertura de negociaciones de adhesión. Sin embargo, el veto griego apareció y ni el apoyo del Parlamento Europeo en 2010 le ha servido a Skopie, hasta el día de hoy, para abrir negociaciones con la Unión Europea respecto a su incorporación. ${ }^{61}$

Grecia, en ambas citas, justificó su oposición en la denuncia de las ambiciones territoriales y nacionalistas de Skopie y en la usurpación de una identidad que no le pertenece a su vecino. Y todas sus acusaciones se basaban en un solo elemento: el uso del nombre de Macedonia.

\section{EL CONFLICTO COMO CONDICIONANTE DE LA POLÍTICA EXTERIOR DE SKOPIE}

Durante el periodo yugoslavo, aun cuando se había establecido durante 1969 una oficina de relaciones exteriores en la República Socialista de Macedonia, ésta contaba con un reducido margen de maniobra en términos de su actuar exterior. ${ }^{62}$ Luego de la desintegración de la antigua Yugoslavia, aquellas limitaciones de antaño parecen hacer eco en el presente, pues la república balcánica

cedonia" siempre que fuera acompañado de un elemento descriptivo. Véase: Clive Leviev-Sawyer, "Greece's Newest Messages on Macedonia Name Dispute”, en The Sofia Echo, 15 de abril de 2009, disponible en http:/ / www.sofiaecho.com/2009/04 /15/705737_greeces-newest-messages-on-macedonia-name-dispute

60 Tanjug, "Crvenkovski Rejects Name Proposal", en B92, 11 de octubre de 2008, disponible en http:/ / www.b92.net/eng/news/region-article.php?yyyy=2008 \&mm=10\&dd=11\&nav_id=54152

${ }^{61}$ Carlos Flores Juberías y Marija Atanaskova, "Macedonia y su camino hacia la integración europea: Avances, obstáculos e implicaciones para la región balcánica", Revista CIDOB d'Afers Internacionals, núm. 96, 2011.

62 Dimitar Bechev, Historical Dictionary of the Republic of Macedonia, Lanham, The Scarecrow Press, 2009, p. 79. 
continúa enfrentando grandes obstáculos para lograr independencia en su política exterior, ya que, si antes dependía de las decisiones tomadas en Belgrado, hoy día sus pretensiones de avanzar en sus procesos de integración se han visto frustrados por la contienda onomástica con su vecino meridional.

Una disputa que a simple vista podría parecer trivial se torna preocupante al trastocar los principales ejes de la política exterior de la ARYM. Tales ejes corresponden, según el Ministerio de Relaciones Exteriores, a tres grandes objetivos: el inicio de las negociaciones de adhesión con la Unión Europea, el ingreso como Estado miembro de pleno derecho a la OTAN, y el despliegue de una diplomacia económica que atraiga la inversión extranjera, promueva las exportaciones y estimule al país como destino turístico. ${ }^{63}$

\section{EL TORTUOSO CAMINO EUROPEO}

Desde que la ARYM presentó la solicitud para su candidatura en 2004, la meta de adherirse a la Unión Europea se ha mantenido fija como el primer gran objetivo de su agenda exterior. Sin embargo, a más de una década de distancia, el país no ha podido trascender más allá del reconocimiento como candidato formal, quedando lejos de lograr la apertura de las negociaciones de adhesión.

Como parte de la estrategia para consumar su integración, la ARYM se ha ido europeizando desde sus inicios como república independiente. Comenzó por instaurar una democracia parlamentaria y dio los primeros pasos hacia una economía de libre mercado. Y desde que se convirtió en candidato formal, sus avances han sido más concretos con la implementación del Programa Nacional para la adopción del Acervo Comunitario, los Programas de Preadhesión y con un Plan Nacional de Desarrollo confeccionado para cumplir con los criterios de Copenhague de adhesión a la Unión Europea.

${ }^{63}$ Ministry of Foreign Affairs of the Republic of Macedonia, "Goals and Priorities”, disponible en http://www.mfa.gov.mk/index.php/en/foreign-policy/goa ls-and-priorities 
La estrategia parecía rendir frutos. En octubre de 2009, la Comisión Europea valoró de manera satisfactoria el progreso macedonio en el cumplimiento de sus deberes como candidato y recomendó abrir las negociaciones de adhesión. No obstante, el veto griego se haría presente. A pesar del duro golpe que representó aquel suceso a las aspiraciones de la ARYM, a finales de año la recomendación se reforzó con la liberación del visado para el ingreso de los ciudadanos de la ARYM, serbios y montenegrinos al espacio Schengen. ${ }^{64}$ La medida dio un voto de confianza a los Balcanes Occidentales en su camino hacia la integración europea, aunque en el caso de Skopie no vendría acompañada de mayores esperanzas para iniciar con la segunda fase.

Con el fin de acelerar las reformas y adaptar al país a los estándares europeos en ámbitos clave como el fortalecimiento del Estado de derecho y derechos humanos, el desarrollo de la economía de mercado, las reformas en la administración pública, la libertad de expresión en los medios y la reforma electoral, la Comisión Europea lanzó en marzo de 2012 el Diálogo de Alto Nivel sobre la Adhesión. ${ }^{65}$ Aunque se han registrado resultados en las reformas de todos los ámbitos, el diálogo, que por el momento se encuentra suspendido, no es sustituto de la fase de negociaciones.

En octubre de 2014, Macedonia recibió por parte de la Comisión Europea su último Reporte de Progreso, ${ }^{66}$ el cual contiene la evaluación de los resultados obtenidos en el proceso de adhesión desde octubre de 2013 hasta septiembre de 2014. La Comisión, sin preámbulo alguno, califica al proceso como "estancado". ${ }^{67}$ La dureza del adjetivo no es en vano y demuestra la fatiga de la que, por sus complicaciones, podría ser una de las candidaturas más engorrosas

64 "EU Abolishes Entry Visas for Three Balkan Countries", en Deutsche Welle, 30 de noviembre de 2009, disponible en http://www.dw.de/eu-abolishes-entry-visas-for-three-balkan-countries / a-4952003

${ }^{65}$ Marko Markovski, "The High Level Accession Dialogue and Macedonia”, en Western Balkans, 7 de julio de 2014, disponible en http://europeanwesternbalkans.com/2014/07/07/the-high-level-accession-dialogue-and-macedonia/

${ }^{66}$ European Union: European Commission: The former Yugoslav Republic of Macedonia Progress Report 2014.

${ }^{67}$ Ibid., p. 1 
que haya debido gestionar el organismo. El estancamiento en el que se encuentra la ARYM se atribuye principalmente a la politización de las instituciones estatales, al control de los medios por parte del gobierno, a la falta de confianza en las instituciones del Estado, la justicia selectiva, la situación de la libertad de expresión, así como a la crisis política entre el gobierno y la oposición. Asimismo, se llama la atención en la necesidad de mejorar la situación interétnica y en la implementación de las últimas recomendaciones del Acuerdo Marco de Ohrid. ${ }^{68}$

Aun cuando no son pocos los puntos débiles en la evaluación, se reconoce el progreso del país en términos de administración pública y en cuanto a su activa cooperación policial regional e internacional. De igual forma, la Comisión reconoce el alto nivel de alineamiento de Skopie con el Acervo y declara que, dados los avances, el criterio político puede considerarse cubierto, por lo que insiste en la recomendación de abrir las negociaciones de adhesión. ${ }^{69}$ También el país ha recibido el visto bueno en el criterio económico gracias a los avances en el establecimiento de una economía de mercado. Sin embargo, el desempleo sigue siendo un foco de alerta, especialmente entre los jóvenes; y los esfuerzos han sido insuficientes en cuestiones de transparencia, disciplina fiscal y planeación del gasto público.

En cuanto a la controversia con Grecia por el nombre, el reporte insiste en el hecho de que es esencial una resolución, debido a que el fracaso de las negociaciones sobre dicha cuestión tiene "un directo y adverso impacto en las aspiraciones europeas del país". ${ }^{70}$ Declaraciones en la misma línea han sido replicadas por el Parlamento Europeo que, a finales de 2014, señaló a la ARYM como el más avanzado de los candidatos en cuanto a la adaptación al Acervo se refiere, y enfatizó que la demora en el proceso de integración

68 Ibid., p. 3.

${ }^{69}$ Según el reporte, Macedonia ha completado la mayoría de las reformas en cuanto al sistema judicial y la administración pública, y cuenta con un alto nivel de alineamiento legislativo, aunque enfatiza en el gran reto que tiene el país debido a la politización de las instituciones estatales, la fragilidad de la situación interétnica y la crisis política entre el gobierno y la oposición.

${ }^{70}$ Ibid., p. 1. 
de la república balcánica en la Unión Europea implica costos crecientes para el país y la seguridad regional, además de menguar la credibilidad de la política de expansión de la Unión. Por otro lado, reconoce que, si bien la cuestión del nombre no debería obstaculizar dicho proceso, el bloqueo del Consejo se debe a esta disputa, por lo que, aludiendo a los compromisos adquiridos en Salónica durante el año de 2003, el Parlamento exhorta a Atenas a crear una atmósfera que propicie la resolución de sus diferencias con Skopie "en el espíritu de los valores y principios europeos". ${ }^{71}$

Lo cierto es que ni los años han logrado que la contienda por el nombre deje de perturbar a Europa. En enero de este año, el representante esloveno en la Comisión de Asuntos Exteriores del Parlamento Europeo, Ivo Vajgl, realizó el noveno llamado consecutivo para que el Consejo Europeo comience las negociaciones de adhesión con la ARYM. ${ }^{72}$ La persistencia se debe a que la Comisión Europea mantiene su aseveración de que el país se encuentra listo para iniciar esta etapa y ya ha emitido seis recomendaciones de manera sucesiva para su apertura sin éxito alguno. Todo parece indicar que la solución a la disputa en este organismo se vislumbra remota, especialmente si añadimos el hecho de que, según Charles Tannok, ${ }^{73}$ ni siquiera el mediador Matthew Nimetz ha aceptado la invitación del Parlamento Europeo para hablar del estado de las conversaciones entre la ARYM y Grecia.

Cabe mencionar que, a pesar de las negativas, el país sigue trabajando para cumplir los compromisos del Acuerdo de Estabilización y Asociación y ha buscado incrementar la cooperación con la Unión Europea y sus Estados miembros en diversas áreas del Acervo. De hecho, en su afán por conseguir un lugar entre los 28, la ARYM se integró al Grupo de Combate de la Unión Europea en el ejercicio militar Rampant Lion que tuvo lugar en Bélgica el año

71 European Parliament, "Resolution on the 2014 Progress Report on the former Yugoslav Republic of Macedonia (2014/2948(RSP))".

72 "Greek MPs in EU Parliament Heat Up Debate over Macedonia", en MINA, 21 de enero de 2015, disponible en http://macedoniaonline.eu/content/view/ $26835 / 2 /$

${ }^{73}$ Miembro del Grupo de Conservadores y Reformistas Europeos. 
pasado. ${ }^{74}$ Esta colaboración en materia de seguridad se suma a la de 2006 en Bosnia-Herzegovina como parte de la misión ALTHEA, a la que envió un contingente militar y con la que continúa contribuyendo con una unidad médica. ${ }^{75}$ Todo ello refleja los esfuerzos de la ARYM por lograr cierto reconocimiento y hacerse con un nombre en el campo de seguridad colectiva, mas no los únicos. De manera adicional a su cooperación con las políticas de defensa de la Unión Europea, Skopie se ha enrolado en un importante número de misiones lideradas por la OTAN, organización a la que, al igual que a la Unión Europea, ambiciona integrarse con tenacidad.

\section{OTAN: SOCIOS PERO NO MIEMBROS}

El camino por alcanzar el segundo objetivo no ha sido menos arduo y se remonta hasta 1993, cuando fue adoptada en el parlamento de Skopie la resolución para la adhesión a la oTAN. ${ }^{76}$ Una vez obtenido su estatus como país candidato durante la cumbre de la OTAN en Washington en abril de 1999, la ARYM comenzó a emprender las acciones necesarias encaminadas a cumplir con el Plan de Acción de Membresía (MAP, por sus siglas en inglés). ${ }^{77} \mathrm{El}$ plan exige una serie de reformas en el ámbito de la defensa y del sector

74 "EU Battle Group, Including Macedonian Army Troops, Ends Military Exercise”, en Republika English, 13 de junio de 2014, disponible en: http:/ / english.republika.mk/?p=122099

${ }^{75}$ Ministry of Defence of the Republic of Macedonia, "Contribution of the Republic of Macedonia to the EU Crisis Management Military Operation ALTHEA in Bosnia and Herzegovia", disponible en http:/ /www.morm.gov.mk/?page_id=701 \&lang=en

${ }^{76}$ NATO, Resolution 817 (1993).

${ }^{77}$ El Plan de Acción de Membresía es un programa de asesoría, asistencia y apoyo práctico diseñado para los países que aspiran a ser miembros de la otan. En él, los solicitantes presentan un programa nacional anual de su preparación para convertirse en miembros en áreas como política, defensa, economía, recursos, seguridad y aspectos legales. Los países reciben a cambio la retroalimentación por parte de la organización en términos de asesoría política y técnica, y reuniones anuales entre ambas partes. NATO, "Membership Action Plan", 10 de junio de 2014, disponible en http://www.nato.int/cps/en/natolive/topics_37356.htm 
de seguridad, las cuales forman ya parte de la nueva Agenda del Ministerio de Defensa. ${ }^{78}$

Fue también en 1999 cuando la ARYM, empeñada por complacer a Occidente, se enroló en su primera misión de apoyo a la OTAN durante la intervención en Kosovo. ${ }^{79}$ La joven república se convirtió en una pieza clave, pues además de recibir una gran cantidad de refugiados albanokosovares, permitió el despliegue de las tropas de la Alianza en su territorio para frenar la propagación del conflicto y otorgó apoyo logístico para las fuerzas de Kosovo Force asistiendo como país de tránsito.

No obstante, los logros que había alcanzado el país en su cooperación con la отAN durante la guerra de Kosovo sufrieron un revés cuando estalló el conflicto armado con la minoría albanesa. Esta crisis, si bien fue superada con relativa rapidez gracias a la ya referida intervención de la comunidad internacional, significó un paso atrás en su proceso de integración. La vulnerabilidad expuesta por Macedonia para enfrentar este reto dio paso a que, luego de la firma del Acuerdo Marco de Ohrid, la OTAN permaneciera en el país e implementara las operaciones Essential Harvest y Amber Fox, y la misión de paz Allied Harmony, con presencia en su territorio hasta el 2003, cuando la Unión Europea la reemplazó. ${ }^{80}$

Pero su cooperación con la Alianza no se limita a los alcances regionales, sino que ha colaborado, incluso, en operaciones lideradas por la отAN fuera del espacio euro-atlántico. Ejemplo de lo anterior ha sido su activa participación en Afganistán, incorporándose a la Fuerza Internacional de Asistencia para la Seguridad

${ }^{78}$ Otros requerimientos del plan son una mayor representación de las minorías étnicas en las estructuras civiles y militares, así como la reforma judicial y policiaca. De manera adicional, la OTAN señala como prioridades la búsqueda para alcanzar los estándares democráticos que aseguren elecciones justas, el combate a la corrupción y al crimen organizado, la mejora de la administración pública y la promoción de buenas relaciones con los Estados vecinos. NATO “NATO's relations with Former Yugoslav Republic of Macedonia”, 22 de agosto de 2014, disponible en http:/ / www. nato.int/cps/en/natohq/topics_48830.htm

${ }^{79}$ Loc. cit.

${ }^{80}$ Robert Serry, "La odisea balcánica de la OTAN", Revista de la OTAN, invierno de 2003, disponible en http://www.nato.int/docu/review/2003/issue4/spanish/ art3.html 
(ISAF, por sus siglas en inglés) en agosto de 2002 como parte del contingente turco. Doce años después, una vez que la ISAF concluyó su misión de combate a finales de 2014, la OTAN echó a andar una misión de relevo conocida como Resolute Support; una vez más, la ARYM se sumaría a las filas de la Alianza. ${ }^{81}$ El persistente candidato, como parte de su asistencia a las acciones en Afganistán post2014, envió 38 efectivos a Resolute Support y para 2015 autorizó una modesta contribución de mil dólares destinada al Fondo Fiduciario para el Ejército Nacional Afgano. ${ }^{82}$

Además de la colaboración con las misiones de la OTAN, el respaldo del parlamento de Skopie -guiado por la perspectiva de que una mayor participación en operaciones en el exterior impulsa su integración euro-atlántica- ha permitido que el país se embarcara en otras grandes operaciones. En 2003 se adhirió a la coalición militar liderada por Estados Unidos en el marco de su lucha contra el terrorismo en la operación Iraqi Freedom, enviando un total de 490 miembros de sus fuerzas armadas, cuya actuación se extendió hasta diciembre de 2008. ${ }^{83}$ Asimismo, Skopie ha estado brindando un limitado pero constante soporte en algunas misiones de mantenimiento de paz de las Naciones Unidas. Las primeras fueron en Liberia en 2006, con el envío de un oficial para trabajar en cuestiones de género, y desde 2007 en Líbano, con un oficial en el Centro de Operaciones Conjuntas en Naqoura. ${ }^{84}$

${ }^{81}$ Lanzada por la OTAN el primero de enero del año en curso, la misión Resolute Support cuenta con la participación de 42 países y tiene como objetivo brindar asesoría, entrenamiento y asistencia a las fuerzas afganas de seguridad y sus instituciones. Véase: Ministry of Defence of the Republic of Macedonia, "Participation in ISAF Mission in Afghanistan", disponible en http://www.morm.gov.mk/?page_ id $=693 \&$ lang $=$ en

${ }^{82}$ Véase: NATo, "Resolute Support Mission (RSM) key facts and figures" , disponible en http://www.nato.int/nato_static_fl2014/assets/pdf/pdf_2015_02/201 50227_1502-RSM-Placemat.pdf; NATO, “ANA Trust Fund”, disponible en http:// www.nato.int/nato_static_fl2014/assets/pdf/pdf_2015_02/20150227_2015-02ANA-TF.pdf

${ }^{83}$ U.S. Central Command, "Macedonia", disponible en http://www.centcom. mil/en/about-centcom-en/coalition-countries-en/macedonia-en

${ }^{84}$ Andreja Bogdanivski, "Contributor Profile: The Republic of Macedonia”, en Providing for Peacekeeping, 17 de agosto de 2014, disponible en http://www.pro- 
Desde que envió su solicitud para ingresar en la OTAN en 1993, la ARYM ha buscado tenazmente un acercamiento y, el hecho de no haber alcanzado aún su estatus como miembro de pleno derecho, no le ha limitado para ser un candidato sumamente activo. Sin embargo, la voluntad y las tareas realizadas para conseguir su adhesión formal no han sido suficientes, aunque tampoco puede decirse que sean desestimadas por la Alianza. En marzo de este año, el secretario general de la otan, Jens Stoltenberg, en una reunión con el primer ministro Nikola Gruevski, ${ }^{85}$ reconoció la restructuración del sector de defensa de la ARYM para adaptarse a los estándares de la organización y asílograr la capacidad de interoperabilidad de su ejército. ${ }^{86} \mathrm{Y}$ en una declaración no menos importante, Stoltenberg señaló que "los avances en las reformas dependen del diálogo democrático efectivo, la confianza generalizada en el Estado de derecho y la libertad de los medios de comunicación", ${ }^{87}$ y reiteró, como se ha venido haciendo en las sucesivas cumbres, que "una solución mutuamente aceptable a la cuestión del nombre debe ser alcanzada antes de que Macedonia pueda integrarse a la OTAN". 88

El problema se presenta a la hora de la votación pues, al ser una organización que toma decisiones por consenso, el fantasma de la disputa por el nombre vuelve a manifestarse en el veto griego y, cual Sísifo, la ARYM, a un paso de alcanzar la cima, ve nuevamente

vidingforpeacekeeping.org/wp-content/uploads/2013/02/Macedonia-Bogdanovski-17-August.pdf

85 "Macedonian PM Meets NATO Sec General", en MINA, 11 de marzo de 2015, disponible en http://macedoniaonline.eu/content/view/27097/2/

${ }^{86}$ Se ha anunciado que el proceso de modernización del ejército que inició en 2012 culminará este año. Y todo parece indicar que el país se encuentra listo para demostrarlo, pues en palabras de Jordan Tasev, analista militar del Consejo Euro-Atlántico de Macedonia, "si llega el momento de emplear la experiencia que obtuvieron nuestros soldados en Afganistán e Iraq, sería probablemente en una operación contra el Estado Islámico", en "Macedonia Revamps Military", Turkish Weekly, 12 de marzo de 2015, disponible en http://www.turkishweekly.net/news/ 181643/macedonia-revamps-military.html

87 "Macedonian PM Meets NATO Sec General", en MINA, 11 de marzo de 2015, disponible en http://macedoniaonline.eu/content/view/27097/2/

${ }^{88}$ Loc. cit. 
la roca rodar cuesta abajo y se prepara para recomenzar con la esperanza de la próxima cumbre.

\section{La Diplomacia Económica de Skopie, una apuesta} AL NACIONALISMO

De acuerdo con Graan, el fracaso de la promesa para la integración euro-atlántica a causa del veto griego en la Cumbre de Bucaest durante 2008 "reforzó el apoyo al gobierno de derecha nacionalista de Nikola Gruevski [y marcó el momento en que] los esfuerzos macedonios para lograr la inclusión política en la OTAN y la Unión Europea fueron rivalizados por proyectos de alto perfil que buscaran el reconocimiento de la economía global". ${ }^{89}$ En este contexto, la ARYM apostó por una estrategia que dependiera menos de terceros para la formulación del último eje de su política exterior: la diplomacia económica. De éste se desprenden tres grandes objetivos: posicionar a la ARYM como un país atractivo para la inversión extranjera, estimular las exportaciones y, finalmente, la promoción del país como destino turístico. La tarea de concretar los dos primeros puntos del programa fue delegada a la Agencia de Inversión Extranjera y de Promoción de Exportaciones de la República de Macedonia.

Bajo el nombre de Invest Macedonia la institución ha implementado en los últimos años una serie de reformas para atraer a los capitales extranjeros, ${ }^{90}$ lo que le ha valido para posicionarse como la economía más favorable a la actividad empresarial en el sureste europeo y la trigésima entre las 189 economías evaluadas. ${ }^{91}$

${ }^{89}$ Andrew Graan, "Counterfeiting the Nation? Skopje 2014 and the Politics of Nation Branding in Macedonia”, Cultural Anthropology, vol. 28, núm. 1, 2013, pp. 161-179.

${ }^{90}$ Entre estas medidas destacan los bajos costos operacionales, incentivos fiscales (tasa única de $10 \%$ para personas físicas y morales, y la exención total de impuestos para los ingresos reinvertidos en el país), subvenciones, mano de obra barata, creación de zonas de desarrollo tecnológico y el libre acceso al mercado europeo.

91 The World Bank, "Doing Business 2015: Going Beyond Efficiency", Washington, 2014. 
En cuanto al estímulo de las exportaciones, la estrategia apunta a la promoción de las empresas nacionales en el extranjero y al desarrollo de proyectos de branding de los productos domésticos. No conformándose con ser una institución gubernamental, Invest Macedonia declara como su principal propósito ser "una organización de servicio profesional y proactivo orientado a satisfacer las necesidades de la comunidad empresarial", ${ }^{92}$ lo que permite ver las pretensiones de la ARYM de convertirse en un gran centro para los negocios. No obstante, los incentivos en materia de inversión y el apoyo a las exportaciones de poco servirían sin una estrategia de proyección internacional que pusiera los ojos del mundo en la pequeña y joven república.

Con el afán de convertirse en un destino atractivo tanto para inversores como para el turismo internacional -tercer punto del eje-, la ARYM se ha empeñado en presentar una imagen deslumbrante al exterior, convirtiéndose ésta en el punto medular de su propuesta de diplomacia económica. Para lograrlo, el gobierno de Skopie se embarcó en una empresa de dimensiones descomunales, la más grande desde la reconstrucción de la capital luego del devastador terremoto de 1964. Durante su presentación oficial en 2010, Skopie 2014 fue anunciado como el proyecto que se encargaría de transformar la sombría imagen de la ciudad -herencia del periodo socialista- en una ciudad sofisticada a la altura de las grandes capitales europeas. Paradójicamente, para este proyecto de renovación, la república ha debido escarbar en su más remoto pasado y ha creado un puente directo que conecta al antiguo Reino de Macedonia con el presente, dejando enterrados más de dos milenios de historia.

El proyecto consiste en la construcción, en el centro de Skopie, de alrededor de veinte edificios de estilo neoclásico o barroco que incluyen museos, teatros, salas de conciertos, hoteles y oficinas administrativas, así como un complejo que conmemora a los héroes caídos y la remodelación de fachadas y puentes para armonizarlos

92 Invest in Macedonia, "Welcome to Invest Macedonia", disponible en http://www.investinmacedonia.com/about-us 
con el nuevo rostro de la ciudad. ${ }^{93}$ Además de las edificaciones, las calles de la ciudad han sido pobladas por un ejército de grandes personajes de la historia y el arte macedonio de desmesuradas proporciones, inmortalizados en mármol y bronce. Las más grandes de ellas son las de Filipo II y la de Alejandro Magno, siendo esta última un nuevo motivo de disputa entre Grecia y la ARYM. Erigida en la plaza principal de Skopie durante 2012, la estatua a la que hoy se refieren como Guerrero a caballo, y de innegable parecido a Alejandro Magno, muestra en su pedestal las batallas míticas del conquistador. El guerrero, que eleva su espada desafiante a casi treinta metros de altura, tuvo un costo de 10.5 millones de euros y es un claro reclamo de la herencia del antiguo Reino de Macedonia por la ARYM. ${ }^{94} \mathrm{Y}$ dado que el monumental guerrero no podía quedar desprovisto de una colosal entrada, se ordenó la construcción de la Puerta de Macedonia, que de igual forma contiene pasajes históricos en los que se representa a Alejandro Magno, y que fue inaugurada en 2012 con motivo de la conmemoración del vigésimo primer aniversario de la independencia de la ARYM.

Pero ni el desafiante guerrero ni la monumental puerta lograron intimidar a Grecia, que puso un alto a los festejos al emitir una queja oficial alegando que Skopie no estaba cooperando para resolver la disputa del nombre. ${ }^{95}$ Esta queja se sumó a la irritación que había provocado en los griegos el caso del aeropuerto de Skopie, que, a finales de 2006, fue renombrado como Aeropuerto Alejandro el Grande, ${ }^{96}$ así como la principal autopista cuyo nombre

93 "Skopje 2014: The New Face of Macedonia Updated", en Balkan Insight, 7 de junio de 2013, disponible en http://www.balkaninsight.com/en/gallery/skopje-2014

${ }^{94}$ Mayer, Till, "Macedonian Makeover: Europe's Flailing Capital of Kitsch”, en Spiegel Online, 12 de noviembre de 2013, disponible en http://www.spiegel. $\mathrm{de} /$ international/europe/macedonian-capital-skopje-gets-kitsch-makeover-viaskopje2014-project-a-933154.html

95 “Athens Complains about Skopje Arch", en Ekathimerini, 12 de enero de 2012, disponible en http://www.ekathimerini.com/4dcgi/_w_articles_wsite1_1_ 12/01/2012_422412

96 Dimitar Bechev, Historical Dictionary of the Republic of Macedonia, Lanham, The Scarecrow Press, 2009, p. 11. 
fue cambiado a Alejandro el Macedonio, y la arena deportiva que honra a Filipo II de Macedonia.

Según un estudio realizado por el Instituto de Ciencias Sociales y Humanidades de Skopie, el objetivo de Skopie 2014 consiste en "afirmar la identidad nacional percibida bajo ataque dada la privación del derecho de la República de Macedonia a hacer uso del nombre 'Macedonia' como identificación del Estado", 97 y señala que la incorporación de la historia antigua en la actual formación de la identidad de la ARYM es una "respuesta a la frustración causada por los eventos que tuvieron lugar en la cumbre de Bucarest de la OTAN en 2008 y al requerimiento específico de la Comisión Europea de resolver el asunto del nombre antes de iniciar las negociaciones de adhesión". ${ }^{98}$ Sin embargo, la estrategia resulta excluyente con los grupos étnicos minoritarios como los albaneses, turcos, serbios o roma, que conforman $36 \%$ de la población y que han manifestado su descontento ante lo que consideran es un proyecto en el que no se sienten representados. ${ }^{99}$

El gobierno de Gruevski buscaba atraer los ojos del mundo a Macedonia con Skopie 2014 y lo ha conseguido, aunque no de la forma esperada. Las críticas desde el exterior han sido severas y, lejos de deslumbrar con el esplendor de una gran capital, al proyecto parece no tomársele en serio. Se lo ha calificado desde ridículo hasta falso e incluso Der Spiegel llegó a compararlo con Las Vegas debido a su "estilo arquitectónico kitsch histórico". ${ }^{100}$ Pero

97 Katerina Kolozova, Kalina Lecevska, Viktorija Borovska y Ana Blazeva, "Skopje 2014 Project and Its Effects on the Perception of Macedonian Identity among the Citizens of Skopje”, Institute of Social Sciences and Humanities, Skopie, 2013.

${ }^{98}$ Loc. cit.

${ }^{99}$ Según el último censo realizado en el 2002 por la Oficina Estatal de Estadísticas de la República de Macedonia. Asimismo, en una encuesta realizada por el Instituto de Ciencias Sociales y Humanidades de Skopie, sólo 7.6\% de los macedonios étnicos entrevistados consideran el periodo antiguo como el más importante para la formación de la identidad Macedonia; y $73 \%$ considera que la construcción de los edificios y monumentos de Skopie 2014 no debería continuar. "Skopje 2014 Poll”, Institute of Social Sciences and Humanities Skopje, disponible en https:// infogr.am/skopje-2014-poll-results-by-isshs

100 Till Mayer, "Macedonian Makeover: Europe's Flailing Capital of Kitsch”, 
las críticas no se quedan fuera de las fronteras pues, en el interior del país, las voces de la inconformidad también se han hecho escuchar y han manifestado su descontento debido al descomunal derroche de recursos para su ejecución. El costo original se había estimado en 80 millones de euros, pero, en abril de 2014, el gobierno declaró que había gastado 200 millones de euros, mientras que los críticos sugieren que el costo real podría estar en torno a los mil millones de euros. ${ }^{101}$ En tiempos de crisis, semejantes cifras hacen del enaltecimiento de la ciudad una afrenta para $29 \%$ de población, desempleada, del país, así como para $27 \%$ de la población, que vive bajo la línea de la pobreza, ${ }^{102}$ sin mencionar las fuertes acusaciones que se le han hecho debido a la falta de transparencia en los contratos. ${ }^{103}$

Los avatares históricos por los que ha pasado el territorio de la ARYM han llevado a que se encuentre en un limbo identitario. Sus raíces, que van desde la Antigüedad como parte del Reino de Macedonia, seguido por sus periodos bizantino, eslavo, otomano y su reciente pasado yugoslavo, colocan a la joven república independiente en una situación compleja al definir una marca país distintiva. Si a lo anterior se suma la frustración ante los fracasos para su integración euro-atlántica, el resultado son proyectos desesperados como Skopie 2014, que como estrategia diplomática ha significado un retroceso en las negociaciones mediadas por la onU,

en Spiegel Online, 12 de noviembre de 2013, disponible en http://www.spiegel. de/international/europe/macedonian-capital-skopje-gets-kitsch-makeover-viaskopje2014-project-a-933154.html

101 Guy De Launey, “The Makeover that's Divided a Nation”, en BBC, 30 de agosto 2014, disponible en http://www.bbc.com/news/magazine-28951171

102 Banco Mundial, 2010 y 2013.

${ }^{103}$ El financiamiento para el proyecto provendría del presupuesto estatal. Sin embargo, a pesar del recorte de 120 millones de euros que éste sufrió en 2012 debido a la crisis que continúa azotando a Europa, la remodelación no se detuvo, por lo que se especula que se ha echado mano de los créditos de adquiridos durante ese año con la banca extranjera e instituciones financieras para mantenerlo en marcha y que suman un aproximado de 700 millones de euros. Siniša Jakov, Marušić "Projekat Skoplje 2014 napreduje uprkos krizi”, Balkan Insight, 12 de junio de 2012, disponible en http://www.balkaninsight.com/en/article/projekatskoplje-2014-napreduje-uprkos-krizi 
pues ha sido interpretado como una provocación para Grecia, lo que dificulta cada vez más la solución a la gastada disputa.

\section{Conclusiones}

A más de dos décadas de distancia de haber proclamado su independencia, la ARYM enfrenta los grandes retos de un Estado pequeño inserto en una región sumamente compleja. Las dificultades que le ha acarreado la reticencia de Grecia a reconocer, en un principio, su legitimidad como Estado y nación y, actualmente, la controversia que le impide hacer pleno uso de su nombre constitucional, han propiciado el surgimiento de sentimientos nacionalistas en ambos países.

El temor de Grecia a las reivindicaciones territoriales sobre su provincia del norte ha sido el argumento bajo el que ha vetado el ingreso de la ARYM a la Unión Europea y a la OTAN, y que, a su vez, le ha servido para alimentar el nacionalismo de su población, que protesta ante lo que considera el arrebato de una parte sagrada de su patrimonio histórico y cultural. El boicot griego se contrapone al reconocimiento otorgado por más de 130 países que reconocen el nombre de República de Macedonia y atenta contra la soberanía de Skopie al limitar el desarrollo de su política exterior.

Por otro lado, el nacionalismo que se ha despertado en Macedonia radica precisamente en la imposibilidad de tener una relación simétrica con Grecia. Se trata de un nacionalismo defensivo que no por calificarse como tal es menos nocivo. Ese nacionalismo defensivo se convierte en la trampa que, ante el exterior, aparentemente une a la sociedad de Macedonia frente a las hostilidades de Grecia pero que, de manera simultánea, la divide en el interior de sus fronteras.

Además de las afectaciones a la política exterior que ha causado la cuestión del nombre, la política interior del país también se ha visto influida por esta problemática. El nacionalismo que se ha despertado a raíz de los fracasos diplomáticos y que ha jugado un papel fundamental en la formación de la identidad de los macedonios como nación independiente puede convertirse en una 
amenaza para la estabilidad del país. El afán por legitimar a la nación macedonia ante los ojos del mundo desemboca en proyectos como Skopie 2014, con el cual, al excluir a las minorías étnicas del país, debilita el pluralismo y exacerba el divisionismo de su sociedad. El proyecto, que fue percibido por Grecia como una clara provocación, muestra los altos costos, tanto económicos como políticos, de importar del esplendor del pasado un poco de brillo para el presente.

A nivel regional, el fin de la disputa onomástica podría menguar los sentimientos nacionalistas que se encuentran latentes, propiciando un mayor nivel de estabilidad y seguridad, dos elementos indispensables al considerar la historia reciente. De hecho, la integración de la ARYM en la OTAN es un paso indispensable en la estrategia de la Alianza para consolidar su ampliación hacia los Balcanes Occidentales, lo que a su vez lleva a cuestionar el hecho de que la organización solape, año tras año, el veto griego.

Es absurdo que Grecia, estando bajo el amparo de la Unión Europea y la OTAN, arguya sentirse amenazada por la pequeña ARYM, no sólo por las reducidas capacidades militares de ésta, sino por su pretensión de adherirse a ambos organismos. Argumentos como éste sólo demuestran la falta de disposición por parte de Grecia de alcanzar un acuerdo en el corto plazo. Y el asunto se complica más al considerar que, mientras para Skopie la resolución de la disputa del nombre es una cuestión de primer orden, la ardua situación por la que está atravesando Grecia hace que sus prioridades estén concentradas en el alivio de su crisis económica.

A pesar de los nexos comerciales que unen a ambos países desde la firma del acuerdo interino en 1995, no ha sido posible acortar la profunda brecha política que los separa. Lo cierto es que, debido a su cercanía, la ARYM y Grecia están irremediablemente condenadas a relacionarse, por lo que un acuerdo político es de suma importancia para fomentar las relaciones de buena vecindad. Con todo, si la posible solución al problema continúa visualizándose a través del cristal de un juego de suma cero, es evidente que ninguno de los posibles escenarios será completamente satisfactorio para ambas partes. Semejante intransigencia vuelve inútiles las propuestas de los mediadores de las Naciones Unidas, pues 
la balanza se inclina a favor de la obstinación. Para alcanzar un acuerdo, es necesario que ambos países reconozcan la necesidad de ceder en las negociaciones. Por el lado de Grecia, es fundamental la disminución de las hostilidades contra la ARYM, a la vez que ésta última debe cesar en sus provocaciones. En síntesis, es neecesario evitar que las "fuerzas profundas" del sentimiento nacional y el nacionalismo, tan presentes a lo largo de esta disputa, rijan las relaciones entre ambos Estados.

Llegará entonces el momento en el que, una vez normalizadas las relaciones de vecindad, la ARYM deje de arrastrar en el nombre la impronta de su pasado yugoslavo y pueda comenzar una nueva etapa en su historia, con la libertad de ejercer su política exterior sin depender de la voluntad griega, mientras que, en el interior, desaparezca el caldo de cultivo para un nacionalismo que ha servido de pretexto a los líderes para ignorar los retos que enfrenta su país, el cual a veinte años de su independencia, tiene una larga lista de retos en materia económica, social y política para concluir su proceso de transición. Y en cuanto a la nacionalidad, incluso si la ARYM debiera aceptar un adjetivo que acompañe su denominación, los ciudadanos macedonios que se consideran como tales no dejarán de serlo pese al cambio en sus pasaportes. Recordando a Denitch, "la única identidad nacional políticamente relevante es la subjetiva: la gente es lo que cree que es". ${ }^{104}$

\section{BibLiografía}

Bechev, Dimitar, Historical Dictionary of the Republic of Macedonia, Lanham, The Scarecrow Press, 2009.

Calvocoressi, Peter, Historia política del mundo contemporáneo, Madrid, Akal, 1999.

Coulombis, Theodore A., Theodore C. Kariotis y Fotini Bellou, Greece in the Twentieth Century, Nueva York, Routledge, 2003.

${ }^{104}$ Bogdan Denitch, Nacionalismo y etnicidad. La trágica muerte de Yugoslavia, México, Siglo XXI, 1995, p. 112. 
Cowan, Jane K., Macedonia: The Politics of Identity and Difference, Londres, Pluto Press, 2000.

Danforth, Loring M., The Macedonian Conflict, Princeton, Princeton University Press, 1997.

Denitch, Bogdan, Nacionalismo y etnicidad. La trágica muerte de Yugoslavia, México, Siglo XXI, 1995.

European Stability Initiative, "Europe's Border Revolution and the Schengen White List Project (SWP)" / "Moment of Truth. Macedonia, the EU budget and the Destabilisation of the Balkans”, Berlín/Bruselas/ Estambul, ESI, 2005.

European Union, "European Commission: The Former Yugoslav Republic of Macedonia Progress Report 2014".

Flores Juberías, Carlos, "Macedonia: entre la crisis y la consolidación", Revista CIDOB d'Afers Internacionals, núm. 51-52, 2000-2001.

Flores Juberías, Carlos y Marija Atanaskova, "Macedonia y su camino hacia la integración europea: Avances, obstáculos e implicaciones para la región balcánica”, Revista CIDOB d’Afers Internacionals, núm. 96, 2011.

Frowein, Jochen A., Max Planck Yearbook of United Nations Law 1997, Leiden, Martinus Nijhoff Publishers, 1998.

Gallagher, Tom, The Balkans in the New Millennium: In the Shadow of War and Peace, Nueva York, Routledge, 2005.

Jeffries, Ian, The Former Yugoslavia at the Turn of the Twenty-first Century, Nueva York, Routledge, 2003.

Klemenčič, Matjaž, The Former Yugoslavia's Diverse Peoples, Santa Barbara, ABC-CLIO.

Kolozova, Katerina, Kalina Lecevska, Viktorija Borovska y Ana Blazeva, "Skopje 2014 Project and Its Effects on the Perception of Macedonian Identity among the Citizens of Skopje", Institute of Social Sciences and Humanities, Skopie, 2013.

Minahan, James, Miniature Empires, Westport, Greenwood, 1998.

Nohlen, Dieter y Philip Stöver, Elections in Europe: A Data Handbook, Baden-Baden, Nomos, 2010.

ONU, "Practice Relative to Recommendations to the General Assembly Regarding Membership in the United Nations", en Repertoire 12th Supplement 1993-1995, capítulo VII, disponible en http://www.un. org/french/docs/cs/repertoire/93-95/93-95_7.pdf 
Osmańczyk, Edmund Jan, Encyclopedia of the United Nations and International Agreements, Nueva York, Routledge, 2002.

Phillips, John, Macedonia: Warlords and Rebels in the Balkans, Londres, I. B. Tauris, 2004.

Renouvin, Pierre y Jean-Baptiste Duroselle, Introducción a la historia de las relaciones internacionales, México, FCE, 2000.

Shea, John, Macedonia and Greece: The Struggle to Define a New Balkan Nation, Londres, McFarland, 1997. 